Full-text Available Online at www.bioline.org.br/ja
J. Appl. Sci. Environ. Manage. .June, 2007

Vol. 11 (2) 95 - 97

\title{
Effect of Temperature on the Tensile Strength and Thermoelectric e.m.f. Values of Aluminium Alloy
}

\author{
*RAY-MARY .N. EGBU \\ Department of Physics, Niger Delta University, Wilberforce Island, Bayelsa State, Nigeria
}

\begin{abstract}
The tensile strength and thermoelectric e.m.f. values of 6063 aluminum alloy quenched at different temperatures from $250^{\circ} \mathrm{C}$ to $600^{\circ} \mathrm{C}$ were investigated. The result empirically confirmed that a perfect correlation exists between the tensile strength and thermoelectric e.m.f. values with concurrent minimum temperature values at about $400^{\circ} \mathrm{C}$. Two distinct temperature range of heat treatments were identified; the low temperature heat treated materials (from $250^{\circ} \mathrm{C}$ to $400^{\circ} \mathrm{C}$ ) yielded both higher tensile strength and thermoelectric e.m.f. values as against the high temperature $\left(450^{\circ} \mathrm{C}\right.$ to $\left.600^{\circ} \mathrm{C}\right)$ heat treated materials. Significantly, these distinct temperature ranges of heat treated materials can be applied as transducer in electrically controlled heat processes. @JASEM
\end{abstract}

The metallurgical success achieved in recent years in the field of applied science is significantly observed in improving physical properties of metals. Owing to arising needs and great involvement of both mechanical and other physical properties in various structural and non-structural works, different metal treatments are designed to improve these properties. These treatments which involve a combination of heating and cooling operations, timed and applied to a metal or it's alloy in a solid state, produce desired properties (Scientific Encyclopedia, 1995.) Most nonferrous heat treatable alloys with limited solubility utilize precipitation hardening as one functional process of improving tensile strength and other mechanical properties. Precipitation hardening is a diffusion mechanism which depends on created vacancies caused by heat treatment - notably quenching (Callister, 1997) It improves the tensile strength as well as other related mechanical properties of the alloy such as fatigue strength, Young modulus and hardness strength. Depending on the material's temperature, different micro-structural changes (grain sizes) occur in the material. It is a common metallurgical fact that such micro-structural changes which favours increase in tensile strength also enhances other related mechanical properties.

However, there has been outstanding interest to ascertain if a micro-structural change that favours a mechanical property would also favour a nonmechanical property. This quest had led to this work and other similar works that correlated mechanical property to non-mechanical properties. Owate (1998) showed that there exist a correlation between dielectric strength and mechanical break down of a Nickel-zinc ferrite Again, Luiggi (1984) established the anisotropic (directional) resistivity of Guinier Preston (GP) zones for aluminum-zinc alloy during precipitation hardening. The variation of thermal conductivity with tempering temperature as well as the corresponding increase in resistivity with tempering temperature have also been studied . (Onyeji et al., 1992). Cottrell (1985) reported that the resistivity of an alloy of supper lattice composition can thus vary sensitively with the heat treatment according to the state of order produced. In a similar way this work therefore considered the dependence of the tensile strength of an aluminum alloy and its thermoelectric e.m.f. values quenched at different temperatures.

\section{EXPERIMENTAL PROCEDURE}

The material used in this work is the 6063 aluminium series. By the A.A.A. standard, (Aluminium Association of America) it is an annealed Aluminium-Magnesium Silicide alloy. Eight paired samples of the 6063 alloy labeled A to $\mathrm{H}$ were prepared for tensile strength testing according to ASTM B557M-81 standard. During machining, the specimens' holes were axially placed along their central axes and crack free gauge lengths were ensured.

Also eight paired strips of the alloy, each having a length of $500 \mathrm{~mm}$ and cross-sectional area of $10 \mathrm{~mm}^{2}$, were prepared and correspondingly labeled A to $\mathrm{H}$ for thermoelectric testing. Each group (labeled $\mathrm{A}$ to $\mathrm{H}$ ) having both tensile and thermoelectric specimens were subjected to different temperature values from $250^{\circ} \mathrm{C}$ to $600^{\circ} \mathrm{C}$ and soaked for one hour. Each group specimens (tensile and thermoelectric specimens), having been soaked at a stated temperature for an hour, were quenched immediately in a brine solution having a concentration of $100 \mathrm{~g}$ per litter of distilled water at $20^{\circ} \mathrm{C}$. The tensile specimens were variously tested using HOUNSFIED tensometer with steady testing speed as recommended by ASTM B557 M- 81 . 
The load and corresponding extension values were converted to stress (load per specimen's crosssectional area) and strain (extension per specimen's original length) values respectively. Each group strips were alternately joined to steel wires in a series arrangement to form a thermopile. The thermopile's hot junctions (separated from each other) were placed in a clay dish filled with humus-free sand and operated to a temperature of $300{ }^{\circ} \mathrm{C}$. The cold junctions (also separated from each other) were placed in ice chips in a funnel to ensure constant temperature of $0{ }^{\circ} \mathrm{C}$ Each group thermopile so formed is then tested for thermoelectric values by using a potentiometer. Considering the low thermoelectric power of aluminum alloys-about $0.47 \mathrm{v} / \mathrm{k}$ (Nwaorisa,1998; unpubl.) a voltage of $6.0 \mathrm{mv}$ was maintained across the potentiometer wire to ensure mid range balancing.

The average balance lengths attained at operational temperature of $250^{\circ} \mathrm{C}$ for each thermopile (group) were applied to obtain their thermoelectric values.

\section{ESULT AND DISCUSSION}

The results of tensile strength and thermoelectric values with their corresponding soaking temperatures are graphically illustrated in figure 1 .

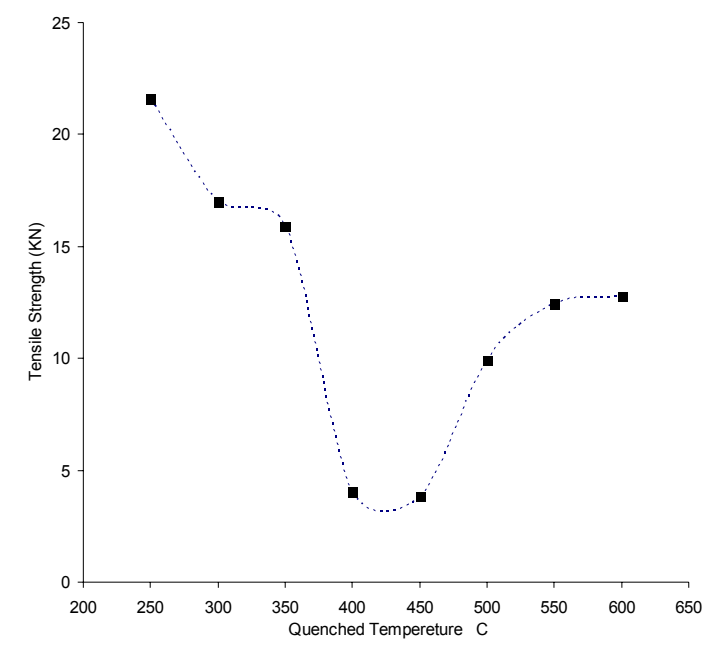

Fig 1. Variation of Tensile Strength $(\mathrm{KN})$ and Thermoelectric e.m.f. (mv)

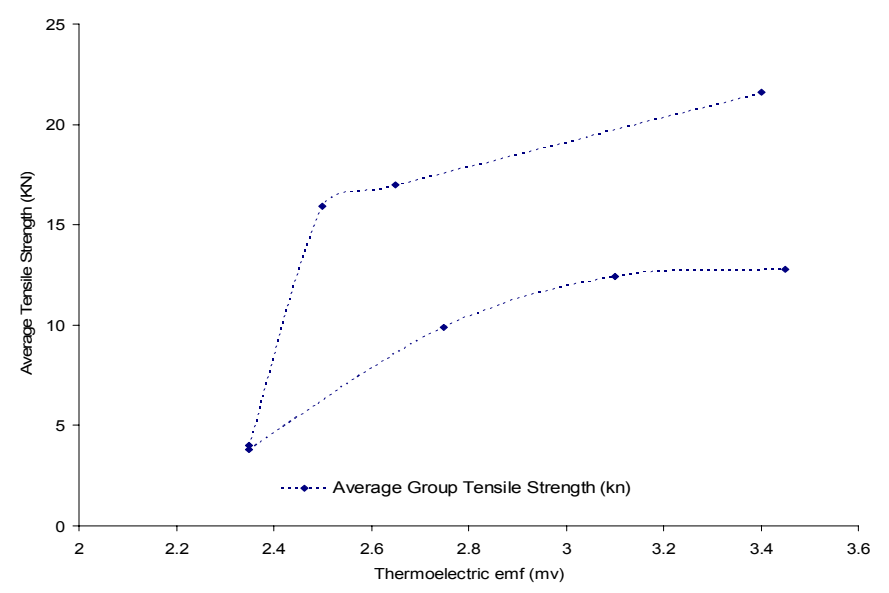

Fig 2. Correlation of Tensile Strength (KN) with Thermoelectric e.m.f. (mv)

From the graphs, remarkable similarities exist. There is an initial fall in both thermoelectric and tensile strength values within the temperature range from $250^{\circ} \mathrm{C}$ to $400^{\circ} \mathrm{C}$ for both graphs and a subsequent rise in their values from $450^{\circ} \mathrm{C}$ to $600^{\circ} \mathrm{C}$. Also, both graphs (thermoelectric and tensile strength) show minimum values for materials quenched within the temperature range of $400^{\circ} \mathrm{C}-450^{\circ} \mathrm{C}$. Most aluminium alloy display quench sensitivity at temperature of about $250^{\circ} \mathrm{C}$. Below this range, no formation of saturated solid solution. Consequently, natural aging at $20^{\circ} \mathrm{C}$ or low temperature artificial aging below $100^{\circ} \mathrm{C}-150^{\circ} \mathrm{C}$ do not give rise to decomposition of saturated solid solution with true precipitation of the surplus phase. Rather some surplus solute atoms precipitate only within the crystal lattice of the matrix over extremely small distances, congregating into a dimensional plate like formation of disc called GUINIER-PRESTON (G.P) zones coherent with the matrix.

These particles (coherent G. P. zones) grow in size with increase in temperature and gradually lose coherency (strain) with the parent matrix (Cottrell, 1985). This accounts for the softening (lower tensile strength values) of the materials soaked and quenched within temperature range of $250^{\circ} \mathrm{C}$ to $400^{\circ} \mathrm{C}$. Continuous growth of the G. P. zones give rise to equilibrium true precipitate of the solute atoms at some locations (points) within the solvent. At these points the periodicity of the lattice is distorted leading to incoherent scattering of electron waves and consequent rise in resistivity. The increase in resistivity (decrease in conductivity) reduces the 
operational performance (figure of merit Z) of a thermocouple which, as stated in equation (1), depends on conductivity ( $\boldsymbol{\delta}$ ). Consequently, the thermoelectric e.m.f. values for materials treated within temperature range of $250^{\circ} \mathrm{C}$ to $400^{\circ} \mathrm{C}$ decrease.

\section{(1)}

$$
\mathrm{Z}=\underline{\delta \zeta_{2}}
$$

K
Where: $Z$ - Figure of merit; ${ }_{\text {power; }} \boldsymbol{\delta}$ - Electrical conductivity;

$K-\quad$ Thermal conductivity

Optical micrographs of these materials treated at $200^{\circ} \mathrm{C}$ and $300^{\circ} \mathrm{C}$ confirm that particle size per unit area increased - decreasing tensile strength .

At $400^{\circ} \mathrm{C}$ the tensile strength and thermoelectric e.m.f. show minimum values. Interestingly, the optical micrograph of the material at this temperature confirm that great number of the grown particles have dispersed (dissolved) within the parent matrix least strain. This significant increase in solubility gave rise to new phase transformation. Quenching carried above the transformation temperature (in this case $400^{\circ} \mathrm{C}$ ) results in a new microstructure with smaller average particle size - increasing strain and greater vacancy concentration. Hence, within the temperature range $450^{\circ} \mathrm{C}-600^{\circ} \mathrm{C}$, the tensile strength rises again. Also the dependent of electric conductivity ( $\boldsymbol{\delta}$ ) on vacancy concentration ( $\boldsymbol{\mu}$ ) as stated in equation (3) vindicates the appreciable rise in conductivity with temperature.

$$
\delta_{=\mathrm{A}} \boldsymbol{\mu}_{\exp }^{\frac{-\Delta \mathrm{H}}{R T}}
$$

Consequently, from equation (1) the thermoelectric e.m.f. values for materials quenched from $450^{\circ} \mathrm{C}$ to $600^{\circ} \mathrm{C}$ increase.

The values of tensile strength are plotted against corresponding thermoelectric e.m.f. values and illustrated in fig. 2. The graph is a combination of two curves which intersect at point $\mathrm{M}$ where both thermoelectric e.m.f. and tensile strength values of the materials have their minimum values. The upper curve (ML) represents tensile strength and corresponding thermoelectric e.m.f. values for materials heat treated from $250^{\circ} \mathrm{C}$ to $400^{\circ} \mathrm{C}$ (Low temperature treatment curve). The lower curve (MH) represents tensile strength and corresponding e.m.f. values for materials heat treated form $400^{\circ} \mathrm{C}$ to $600^{\circ} \mathrm{C}$ (high temperature treatment curve).

Conclusion: The results of this work have empirically confirmed that there exist a perfect correlation between the tensile strength and thermoelectric e.m.f. values.

Based on the concurrent minimum values for both tensile strength and thermoelectric e.m.f., two distinct temperature range of heat treatments are identified; i).Low temperature treatment range $(\mathrm{ML}$ - materials quenched from $250^{\circ} \mathrm{C}$ to $400^{\circ} \mathrm{C}$ ) and ii).High temperature treatment range $(\mathrm{MH}-$ materials quenched from $400^{\circ} \mathrm{C}$ to $600^{\circ} \mathrm{C}$ ). For a given thermoelectric value the tensile strength depends on the degree of quenching.

Low temperature quenched materials have greater strength than high temperature quenched materials for the same thermoelectric values. In any industrial application which requires optimum utilization of both physical parameters, the low temperature treated material is preferred. It's tensile strength/thermoelectric e.m.f. ratio at any given thermoelectric value is greater than the high temperature treated material.

\section{REFERENCES}

Annual book of ASTM standards. part 7, B597 - 80 (1982). Heat treatment of Aluminum alloy. pg 36 and 754, part 10, B557 M - 80 (1982). Tension testing wrought and cast Aluminum and magnesium alloy product (metric). pg $124-134$

Callister, D W Jr (1997). Material Science and Engineering, An Introduction. John Wiley and Sons. pg 334-337.

Cottrel, A (1985). An Introduction to metallurgy. ELBS and Edward Arnold publishers. pg 365 - 370, 486.

David, V R (1995) Thermodynamics of materials Vol. II. John Wiley and Sons Inc. pg 232-233

Luiggi, N J (1984) Anisotropic Resistivity of Guinier Preston zone for $\mathrm{Al}-\mathrm{Zn}$ Alloy during pre precipitation. Journal of Physics, Metal physics. Vol. 14 No 11.pg 2601.

Nworisa, E I (1988). Design and construction of a thermoelectric power generator. B.Sc tech project. Federal University of Technology, Owerri.(unpubl) .

Onyeji, L J I, Nwagbo, E E, Gulma, M A (1992) Modification of steels for solar thermal application.Nigerian Journal of solar energy. Vol. 11.pg $1-16$.

Owate, I O (1998). Correlation between Dielectric and Mechanical Breakdown for Ni-Zn ferrite. Nigerian Journal of Physics. Vol. 10, pg $48-52$.

Oxford Dictionary of Physics, (2000) $4^{\text {th }}$ edition. Alan Isaac ed. nhyn 